\title{
The Spatial Scope of Competition and the Geographic Distri- bution of Entrepreneurship: Magazine Foundings and the U.S. Post Office
}

\author{
Heather A. Haveman, ${ }^{a}$ Christopher I. Rider ${ }^{b}$
}

a) University of California, Berkeley; b) Emory University

\begin{abstract}
We propose that the geographic distribution of entrepreneurship evolves as developing communication systems alter the spatial scope of competition Our arguments imply that as spatial barriers to communication diminish founding events will be less sensitive to local context and more sensitive to distant competition. We test this argument with data on the first modern communication system, the US post office, and foundings of organizations that depended on it for distribution: magazine-publishing ventures. We find that as the postal system expanded, the spatial scope of competition among magazines increased: magazines in distant locations exerted more negative effects on local founding rates, whereas magazines in the focal location exerted less positive effects on local founding rates These findings reveal how spatial barriers to competition shape the geography of entrepreneurial activity.
\end{abstract}

Keywords: competition; technological change; geography; space; entrepreneurship; founding rates

Editor(s): Jesper Sørensen, Olav Sorenson; Received: September 17, 2013; Accepted: October 27, 2013; Published: April 8, 2014

Citation: Haveman, Heather A., and Christopher I. Rider. 2014. "The Spatial Scope of Competition and the Geographic Distribution of Entrepreneurship: Magazine Foundings and the U.S. Post Office." Sociological Science 1: 111-127. D0I: 10.15195/v1.a9

Copyright: (c) 2014 Haveman and Rider. This open-access article has been published and distributed under a Creative Commons Attribution License, which allows unrestricted use, distribution and reproduction, in any form, as long as the original author and source have been credited.

$D_{\text {tion systems that reduce spatial barriers }}^{\text {ESPITE tremendous advances in communica- }}$ to interaction, much research demonstrates the continuing relevance of geography in modern societies. People and organizations remain situated in distinct places characterized by local cultures and laws, site-specific resource constraints, and localized information flows (Fischer 1992; Freeman and Audia 2006; Marquis and Battilana 2009). Both people and organizations continue to cluster in space (Marshall 1920; Porter 1990; Krugman 1991), and their likelihood of interacting increases with proximity (Festinger, Schacter, and Back 1950; Hannan and Freeman 1989). Consequently, when starting new organizations, entrepreneurs typically obtain resources from the communities where they reside (Sorenson and Audia 2000).

Research on organizations and geography is limited, however, by its overwhelming focus on modern research sites where communication systems are well developed and, therefore, spatial barriers to communication are low (for exceptions, see Pred [1973, 1980] and Marquis [2003]) We know far less about how changes over time in the speed, reliability, or cost of communica- tion alter organizational interactions across space Many scholars argue that such advances reduce the "friction of distance" (Janelle 1969) and so reduce geographic constraints on interaction (e.g., McLuhan 1962; Janelle 1968; Pred 1973, 1980; Kern 1983; Giddens 1990; Friedland and Boden 1994).

As spatial barriers to communication fall, social, economic, and political interactions expand in physical space, creating communities and markets that span continents and oceans - increasingly homogenous "global villages" and "world economies" (McLuhan 1962; Janelle 1969; Sassen 2012) Indeed, communication systems like the post office and Internet are often developed specifically to connect geographically distant individuals and organizations (John 1995; Hafner and Lyon 1996) These developments free actors from the constraints of their particular locations and weaken influences of both place (location) and space (distance) on organizations (Marquis 2003) In sum, this argument implies that as spatial barriers to interaction diminish the geographic scope of competition expands, so that organizations compete over greater distances. 
In analyzing how developments in communication systems alter the geographic scope of competition, we focus on organizational foundings because geographic influences are particularly strong at startup. It is widely acknowledged that the geographic distribution of new ventures is especially sensitive to the spatial distribution of established organizations (Sorenson and Audia 2000). But how this relationship changes as spatial barriers to competition fall remains an open question.

In this article, we study the development of the first modern communication system, the U.S. post office (Starr 2004), which was designed to forge bonds among the states (Rich 1924; Kielbowicz 1989; John 1995). Our analysis runs from 1790 , when the postal system was in its infancy, to 1860 , when it was well developed. Because they depended greatly on the postal system for distribution, we study magazine-publishing ventures. Like other media, magazines have been touted as modernizing forces that propelled a shift toward translocal communities, which depend heavily on media like magazines to bind members together (Eisenstein 1979; Anderson 1991; Thompson 1995; Starr 2004).

To ground our analysis in context, we first detail the intertwined histories of the American postal system and magazine industry. We then build on research in sociology, economics, history, and geography to inform expectations about how postal development affected magazine foundings. After detailing our research design, we discuss the empirical results.

\section{The U.S. Postal System and Magazine Industry, 1790 to 1860}

\section{Development of the U.S. Postal System}

At the end of the Revolution, the postal system was rudimentary, slow, and expensive. Only a few miles of routes connected a handful of coastal towns, capacity was limited, and transit was frustratingly slow. Political elites viewed the post office as a tool for creating a national community that would transcend state boundaries, so they worked to improve the postal system (Kielbowicz 1989; John 1995; Starr 2004). In 1787, the Continental Congress enshrined the post office in the Constitution. In 1794, Congress established the post office as a permanent arm of the state and mandated system expansion. The postal system grew rapidly, from 75 offices and almost 2,000 miles of roads in 1790 to 4,500 offices and more than 70,000 miles of roads in 1825 . The postal network was virtually complete by the late 1820 s (John 1995), although the federal government continued to expand it to cover the nation's growing landmass. By 1860, the postal system boasted almost 30,000 offices and 240,000 miles of roads.

Postal system development also involved several improvements in transportation speed and reliability. Before 1825, prompt delivery of the mail was impossible. Dirt roads turned to mud in the winter and spring, slowing travel to less than two miles per hour. Starting in the 1820s, the federal government funded "macadamized" roads that used stones crushed together to make a tough, above-ground surface that allowed water to run off the sides (Ringwalt 1888; Taylor 1951). In the 1830 s, the addition of tar and pitch as sealants to create tarmac made roads smoother and more durable. Travel speed also improved as stagecoaches eclipsed horseback over land routes between 1790 and 1830. Steamboat mail delivery on riverways began in 1813, making upstream travel increasingly fast, cheap, and reliable. Canals were built in two spurts, 1815 to 1834 and 1836 to 1854 , facilitating trans-Appalachian travel. Finally, railroad construction started in 1826 and took off after 1848; by 1860 , more than 30,000 miles of tracks had been laid, making railroads the preeminent means of mail transport.

Postage rates also declined substantially over time. The 1794 Postal Act set very low rates for newspapers and much higher rates for magazines and letters: for carriage less than 500 miles, rates were 1.5 pence for newspapers, 8 pence for magazines, and 25 pence for letters (Kielbowicz 1989:122). Postage rates for magazines remained fairly constant until 1845 , when they dropped to 5.5 cents, then to 4 cents in 1851 and 1.5 cents in 1852 .

In sum, between 1790 and 1860, the federal government created an extensive, reliable, fast, and affordable communication postal system. 


\section{Evolution of the Magazine Industry}

The magazine industry is an excellent research site for examining the impact of communication system development on entrepreneurial activity because magazines depend heavily on postal distribution. Historians of magazines (Mott 193038; Tebbel and Zuckerman 1991) and the post office (Kielbowicz 1989; John 1995) agree that the expansion of the postal system between 1790 and 1860 benefited magazines. As one historian explained, "each new mail route . . . enlarged opportunities for publishers or groups in faraway cities to project their messages onto new audiences" (Kielbowicz 1989:5).

Postal development enabled magazine industry expansion, not the other way around, which facilitates causal inference. Congress authorized post roads and offices, and within the executive branch the postmaster general authorized funding for them. Although establishing post roads and offices was a form of congressional pork, pressure on Congress came primarily from constituents who sought improved delivery of goods and letters, not magazines (Rich 1924; Larson 1987; Kielbowicz 1989; John 1995). Magazine publishers' influence on Congress was virtually nil because magazines constituted only a tiny portion of the mail (Rich 1924; Kielbowicz 1989; John 1995). Not until the 1850s was the magazine industry able to secure significant rate reductions (Kielbowicz 1989:121-39).

After the first magazines were published in 1741, the magazine industry grew very slowly: only 23 were founded before the end of the Revolution. Magazine foundings accelerated after peace was restored, and the number of magazines in print rose from 12 in 1790 to 208 in 1825 . The quarter-century after 1825 - the first golden age of magazines (Mott 1930; Tebbel and Zuckerman 1991) — saw 2,679 magazine foundings and more than 700 magazines in print by 1850. The industry continued to grow until the Civil War; by 1860, almost 1,000 magazines were in print.

The industry expanded geographically along with the nation and the postal system. Magazines were first published along the eastern seaboard, mostly in the Northeast. In the decades after the Revolution, magazines spread throughout the South and along the western frontier. By the 1850 s, magazines appeared in every state and several sparsely settled territories.

\section{Geography and Entrepreneurship}

The terms place and space, which are central to geographical analysis, have many meanings. Geographers conceive of place as a physical territory the boundaries of which are determined by politics or topography; as a social setting where interactions occur and are constituted by informal groups or formal institutions; or as a constellation of meanings, identities, values, and attachments to a locality (Agnew 1987). Space is considered a territory or field that contains many places; a distance, measured in terms of time, effort, or money, to travel from one locality to another; or a web of cultural, economic, or political ties between localities (Hillier and Hanson 1984).

Following common practice in sociology (Gieryn 2000; Logan 2012), we define space as the physical distance between people and organizations in some focal site and those in other sites, which determines how much the physical features, demography, networks, and culture of those other sites affect people and organizations in the focal site. We define place as location, meaning a site's physical features, human and organizational demography, networks, and culture. We restrict our usage to these meanings to develop precise predictions about the relationship between communication systems development and entrepreneurship We distinguish between local entrepreneurs, organizations, resources, and customers (those situated in the focal place) and nonlocal ones (those situated in other places), and we measure the physical distance (space) between places

\section{Importance of Place and Space for Entrepreneurship}

Local organizations and local foundings. Spatial theories of markets imply that connections to place have important implications for new organizations. Demand is rooted in place because customers often economize on search costs by patronizing nearby organizations (Eaton and Lipsey 1982; Stahl 1982). Flows of personnel and industry-specific tacit knowledge, strength in numbers for political mobilization, and sustained attention from customers all become concentrated around locations with many organizations (Krugman 1991; Hannan and Freeman 1989; Saxenian 
1994; Audia and Rider 2010). Additionally, organizational legitimacy depends on the existence of other similar, geographically proximate organizations: the more organizations in a location that are similar to a focal organization, the more local customers, resource providers, and regulatory authorities will view the focal organization as a reasonable way to achieve valued goals (Hannan and Freeman 1989).

Entrepreneurs tend to found organizations where they already reside for both personal and pragmatic reasons (Katan and Morgan 1952; Mueller and Morgan 1962; Sorenson and Audia 2000). Personally, entrepreneurs prefer not to uproot their families and leave their friends. Pragmatically, their access to resources and customers tends to be concentrated around their place of residence, and people do not readily relocate for jobs (Dahl and Sorenson 2010); information networks concentrate in space (Krugman 1991; Sorenson and Audia 2000); and transporting equipment, raw materials, and other physical inputs is costly.

Existing organizations play an important role in the founding of new ones because entrepreneurs often start new ventures after working in local organizations in the same or related industries; their new ventures apply tacit knowledge acquired in local organizations and tap local information and resource networks (Freeman 1986). Even when entrepreneurs move to new locations to start organizations, the spatial distribution of organizations matters: the presence of many other similar organizations signals available resources and informs expectations of new venture success (Appold 2005; Suire and Vincente 2009) ${ }^{1}$ Places with many organizations of a particular form appear to be viable locations for new ventures (Hannan and Freeman 1989), so the spatial distribution of existing organizations strongly influences the spatial distribution of organizational founding. Therefore, prior work informs our baseline expectation that the founding rate in any location will increase with the number of similar organizations in that location (Sorenson and $\mathrm{Au}-$ dia 2000; Audia, Freeman, and Reynolds 2006).

Competition over resources and customers, which deters foundings, is also more intense among

\footnotetext{
${ }^{1}$ Such expectations may not, of course, be fulfilled: new ventures in locations with dense agglomerations of organizations have higher failure rates than those in sparse locations (Sorenson and Audia 2000).
}

more geographically proximate organizations. Although competition increases with the number of organizations in a locality, in an industry's early years, competitive effects are dominated by legitimation effects (Hannan and Freeman 1989). Because our analysis spans the early years of the magazine industry's history, we expect the positive effects of localized knowledge spillovers, resource pools, and legitimation to outweigh the negative effects of competition, but we also test for negative effects of competition.

Nonlocal organizations and local foundings. Founding rates in any location are also sensitive to organizations in other locations. If their current location is sparsely populated - an indicator of scarce resources and thus poor conditions for founding - entrepreneurs are likely to move to densely populated locations, because density indicates resource abundance and thus good conditions for founding. Dense, nearby locations are seen as especially attractive destinations for founder migration (Appold 2005; Suire and Vincente 2009). Thus dense clusters of organizations located near a focal location will draw entrepreneurs away from that location, attenuating founding rates there (Lomi and Larsen 1996). On the basis of previous research, our second baseline expectation is that the founding rate in any location will decline with the number of similar organizations in other nearby locations (Sorenson and Audia 2000). In other words, the greater the spatial proximity of industry incumbents beyond a focal location's boundaries, the lower the founding rate in that location ${ }^{2}$

\section{Advances in Communication Systems Alter the Geography of Entrepreneurship}

Spatial theories of entrepreneurial activity yield baseline expectations for the geography of found-

\footnotetext{
${ }^{2}$ Previous research found positive effects of the number of nonlocal organizations on local founding rates (e.g., Hannan et al. 1995; Bigelow et al. 1997). However, these studies treated all organizations outside a focal location, both near and far, as equally competitive, which obscures limits on the geographic scope of competition. Temporal shifts in the geography of competition-the focus of our analysis - are best observed when spatial effects are explicitly theorized and measured. Therefore, following Sorenson and Audia (2000), we treat competition as a function of distance between locations.
} 
ing, but our primary interest is how geographic influences on founding evolve with advances in communication systems Research in geography has shown that advances in communication systems reduce spatial barriers to interaction: they "shrink" space and expand the geographic scope of interactions among people and organizations (Janelle 1968, 1969; Pred 1973, 1980). Such advances attenuate the impact of space: the distance between new ventures, on one hand, and resources, customers, and competitors, on the other, matters less. It becomes easier for entrepreneurs in any location to acquire resources from distant locations, for example, magazine contents, and it becomes easier for customers to discover and purchase goods produced far from their local communities, for example, magazines published in distant locations. But as spatial barriers to interaction decrease, it also becomes easier for organizations in other locations to compete for customers and other resources in the focal location. We therefore predict that the negative relationship between founding rates in any location and the number of similar organizations in other nearby locations will strengthen as communication systems develop.

Advances in communication systems not only heighten competition between local and nonlocal organizations but also make entrepreneurs less dependent on their local communities for customers and inputs. This happens because local entrepreneurs can more easily reach customers in and acquire inputs from more distant locations. Accordingly, the actual or perceived benefits to entrepreneurs of locating their ventures in places with dense clusters of local organizations diminish. We therefore predict that the positive relationship between founding rates in any location and the number of similar organizations in that location will weaken as communication systems develop.

In sum, we propose that founding rates in a focal location are higher the more organizations are located there and lower the more organizations are located in other nearby locations. We further propose that as communication systems develop, local organizations exert weaker positive effects on founding rates and nonlocal organizations exert stronger negative effects. In short, advances in communication systems attenuate the influence of both space and place (i.e., distance and location) on entrepreneurship by expanding the geographic scope of competition.

\section{Research Design}

We test these predictions by analyzing data on the American postal system and magazine industry from 1790 to 1860 . Our analysis begins in 1790 because that is the first year in which reliable data on many variables are available. It ends in 1860, the year before the Civil War. Only 75 post offices and 49 magazines were founded before 1790, so our analysis covers over 99 percent of antebellum postal development and antebellum magazine foundings. In the following, we define our geographic unit of analysis, explain our data sources and theoretical measures, and describe our analytical methods.

\section{Geographic Unit of Analysis}

In sociological analysis, the concepts of place and space are flexible with regard to scale (Gieryn 2000). Previous research on organizational geography has defined location at several levels of analysis: city or town, county, multicounty labormarket area, state, multistate region, or nation (see Marquis and Battilana [2009] for a review). In this analysis, we define location at the state level for three reasons. First and most important, states were distinct communities in this era and had ultimate authority over most matters of importance to ordinary people (Brown 1976; Wiebe 1984; Anderson 1991). Second, previous research demonstrates strong competitive effects at the state level and weaker influences at the city level (Carroll and Wade 1991; Swaminathan and Wiedenmayer 1991), indicating that many organizations compete across larger geographic regions than municipalities. That is certainly true for the magazines we study: many circulated beyond a single community, even at the beginning of our study period. Among magazines founded between 1790 and 1820, when the postal system was not fully developed, over half of magazines whose geographic scope of distribution we know were sold in multiple states. Third, it was extremely difficult to locate serially and cross-sectionally reliable state-level data on this time period; it would be virtually impossible to assemble data on smaller geographic units. If the municipality, 
rather than the state, bounded competitive dynamics in this time period, then using the state as the unit of analysis will yield conservative tests of our hypotheses because doing so will ignore any competitive effects of magazines published outside the focal municipality but inside the focal state.

In the antebellum era, new states were carved out of existing ones (e.g., Maine from Massachusetts in 1820), created from territories as they were populated by whites (e.g., Tennessee in 1796), entered the Union when the federal government purchased land from colonial powers (e.g., Louisiana in 1803), or created when new territories were ceded by treaty (e.g., California in 1848). To allow consistent comparisons of each place over time, we used state boundaries as of 1860 . That means, for instance, that magazines published before 1820 in the parts of Massachusetts that became Maine were coded as being published in Maine.

\section{Data Sources and Measures}

Data on magazines came from a list encompassing virtually every magazine published in America from colonial times to the Civil War (Haveman 2004, 2013).

Dependent variable: Magazine foundings. This is the number of magazines founded in each state (or city) each year. Our analysis excluded 1.2 percent of magazine foundings (58 of 4,989) for which we could not identify the state of publication

Independent variables: Local and nonlocal magazines. To account for the influences of local magazines, we counted the number of magazines published in each state each year. Because this variable was highly skewed, we added 1 and logtransformed it We also experimented with linear and quadratic terms for number of magazines. We found an inverted-U-shaped effect, but the peak of this effect was above the 98th percentile of state-year observations, indicating that for the vast majority of states and years, the effect increased at a decreasing rate - only in the industry core near the end of our study period did we see evidence of competitive crowding This pattern of results convinced us that using the logged count was appropriate.

To capture the effects of nonlocal magazines, we constructed a distance-scaled count of maga- zines outside the focal state each year. Scaling by physical distance takes into account persistent costs of interacting across space, which means that interactions between in-state (local) and out-of-state (nonlocal) magazines diminish with out-of-state magazines' distance from the focal state Scaling by distance from the focal state also accounts for spillovers from nearby states into the focal state. To compute this variable, we first identified the latitude and longitude of the municipality in each state where the largest number of magazines were published during our study period (e.g., Philadelphia for Pennsylvania, Cincinnati for Ohio, Charleston for South Carolina). Using spherical geometry (for details, see Sorenson and Audia [2000]), we then computed the distance in miles between each state's magazine center. Then, for each state $i$ in each year $t$, we computed the distance-scaled count of out-of-state magazines as follows:

$$
\begin{aligned}
& \text { Distance scaled number of magazines } \\
& \quad \text { outside state } i t=\sum_{j \neq i} \frac{M_{j t}}{D_{i j}}
\end{aligned}
$$

where $M_{j t}$ is the number of magazines in any state $j$ (other than the focal state $i$ ) in year $t$ and $D_{i j}$ is the distance in miles between the magazine centers of the focal state $i$ and the other state $j$. We summed this distance-scaled count over all states other than the focal state 3 States located near the industry centers, which were the largest agglomerations of magazines, scored highest on this variable. For example, in every year, Delaware and Connecticut scored higher on this variable than Georgia and Indiana because the former were closer to the industry centers than the latter.

For a robustness check, we created a national, distance-scaled count of magazines: the number of in-state (local) magazines plus the number of out-of-state (nonlocal) magazines. Each magazine in the focal state was given a weight of 1 , and each magazine in other states was given a weight inversely proportional to its distance from the focal state This variable varies across states in any given year 4

\footnotetext{
3 Scaling out-of-state magazine counts by distance did not produce a highly skewed variable, so it was not necessary to log-transform this variable, as we did with the in-state variable.

4 This variable was not highly skewed, so it was not necessary to log-transform it.
} 
Independent variables: The postal system. We counted the number of U.S. post offices each year, using data from Miles (1855) and Daniel (1941). This variable is constant across states within any given year. For a robustness check, we calculated the number of post offices in each state each year. We obtained state-level data from Annual Reports of the Post Master General to the House of Representatives. Reports were not available for all years; we used reports for 33 out of the 70 years in our study period and generated annual state-level data using linear interpolation. The number of post offices in each state increased continually, so this interpolation is a reasonable approximation. We then created two annual counts: the number of post offices in the focal state and the number of post offices outside the focal state. Both counts vary across states within any given year 5

Interaction terms. We tested predictions about how the impact of local organizations on founding rates changes as communication systems develop by interacting the number of magazines in the focal state with the number of US (or state) post offices. Similarly, we tested predictions about how the impact of nonlocal organizations on founding rates changes as communication systems develop by interacting the distance-scaled counts of magazines outside the focal state with the number of US (or out-of-state) post offices.

Control variables. We controlled for other factors that reflected variation in states' natural attractiveness to magazine entrepreneurs, starting with the lagged dependent variable, the number of foundings in the focal state in the previous year; this specification is more flexible than modeling a change score because it does not constrain the effect of the lagged dependent variable to unity. We controlled for state population, measured in millions. We obtained decennial census data on state-level population (U.S. Bureau of the Census 2001) and interpolated linearly to create annual

5 The ideal measure of advances in communication systems would also capture reductions in travel time because of advances in transportation infrastructure (roads, canals, steamships, and railroads). But precise, timevarying data on point-to-point travel times are simply unavailable for the vast majority of locations. Post offices were built in combination with transportation infrastructure, so post office counts capture much of this variance. And as explained later, we control for post roads in each state, which captures more of this variance. data. State populations increased continuously, so this interpolation is a reasonable approximation. We counted miles of post roads in the focal state, using data from the Annual Reports of the Post Master General, and scaled this variable by state landmass in square miles. We controlled for the postage rate charged for magazines (in cents), based on histories of the post office (Kielbowicz 1989; John 1995). We used a commodity-price index (McCusker 2001) to correct for inflation and express the rate in constant (1860) dollars.

We controlled for each state's literacy rate, to account for demand net of state population. Reliable data on literacy are not available before 1840 (Soltow and Stevens 1981), so we proxied literacy rates by measuring the growth of two important antebellum educational institutions: colleges and Sunday schools. We obtained annual state-level counts of college foundings from Marshall (1995) and computed state-level counts of cumulative college foundings and colleges in operation. We developed state-level counts of Sunday schools from statistics that Boylan (1988) extracted from the American Sunday School Union censuses of 1832 and $18756^{6}$ These variables were highly correlated, so we combined them by conducting a principal components factor analysis. We used an orthogonal varimax rotation and obtained a two-factor solution; we used the predicted values of the largest factor, which we labeled state literacy.

\section{Model Specification and Estimation}

We used panel data on states. The start of each state's time series depended on two events: it must have achieved statehood and it must have experienced at least one magazine founding. We

\footnotetext{
6 We developed this count in three stages. First, we created a start date for each state's time series. If historians (Boylan 1988; Zboray 1993) indicated the precise year the first Sunday school was founded in a state, we used that year. For other states, we estimated the start date on the basis of white settlement patterns. This is reasonable because Sunday schools preceded churches in most frontier settlements (Boylan 1988:34). Second, we extrapolated backward from data for 1832 to each state's start date using an exponential growth function to match the growth of Sunday schools: the national count almost doubled from 2,321 in 1826 to 4,258 in 1832. Third, we interpolated from 1832 to 1875 . Because literacy rates increased with population (Soltow and Stevens 1981), we based our interpolation on the rate of state population growth.
} 
excluded all state-year observations from the year 1815 because the US postmaster general barred magazines from the mail for much of that year. We lagged all explanatory variables by one year to ensure temporal priority and increase our confidence that we captured the correct direction of causal processes. Our data set contains 1,580 state-year observations, but our use of lagged explanatory variables and exclusion of observations from 1815 reduced our sample to 1,529 observations

The dependent variable is a discrete event tracked over time, so we used event-count methods. Because this dependent variable exhibited significant overdispersion, we estimated negativebinomial models. To control for the impact of unobserved and unmeasurable state-specific, timeinvariant factors (e.g., topology), we estimated conditional fixed effects models that group observations by state. To avoid confounding the main effects of our key independent variable (the number of post offices) with other factors that increased over time, we included temporal fixed effects - first for decade, then for year. This approach enables us to check the robustness of our results to progressively aggressive approaches to controlling for omitted variables common to decades or years.

\section{Results}

Table 1 reports descriptive statistics for all variables, whereas Table 2 presents results. Model 1 of Table 2 includes only control variables plus state fixed effects; subsequent models add explanatory variables. Within each state, founding rates increased as more roads were developed, as the state's population increased, and as the US postal system expanded These effects are generally consistent across models.

Model 2 shows that, as expected, magazine founding rates increased with the number of magazines published in the focal state and decreased with the number of magazines published in nearby states. These results reveal the benefits of local (in-state) magazines but also competitive pressures from dense clusters of nearby nonlocal (outof-state) magazines Model 3 includes the interactions of both magazine counts with the count of US post offices. The positive effect of in-state magazines on the magazine founding rate decreased as the postal system expanded: there is a significant positive main effect of the number of in-state magazines and a significant negative interaction between that variable and the number of US post offices. This indicates that the benefits of dense clusters of magazines within the focal state diminished with postal system expansion. In addition, the negative effect of magazines in nearby states on the founding rate increased as the postal system expanded: there is a negative (but no longer significant) main effect of the distance-scaled number of out-of-state magazines and a significant negative interaction between that variable and the number of US post offices. This indicates that the competitive effect of nearby magazines outside the focal state increased with postal system expansion.

Model 4 tests the robustness of these results to the inclusion of unreported decade fixed effects to account for the fact that the number of both magazines and post offices increased over time. This modeling strategy restricts our empirical tests to accounting for within-decade variance in postal expansion. The parameters of interest are robust to including decade fixed effects, as the main effects of in-state and out-of-state magazine counts and their interactions with the count of US post offices are in the same direction as in model 3 , of the same magnitudes, and at the same levels of statistical significance. This increases our confidence in the findings from model 3.

Decade fixed effects do not account for temporal changes common to all states in a given year. Therefore, model 5 replaces decade fixed effects with unreported year fixed effects. We dropped the magazine postage rate and the main effect of the number of US post offices because they vary only over time, so the year fixed effects absorb their influences. We can, however, retain the interaction terms because both in-state and out-of-state magazine counts vary across states each year. In model 5 the coefficients of interest remain robust to the inclusion of year fixed effects, although the coefficient on interaction between the count of out-of-state magazines and US post offices becomes only marginally significant $(p<0.09)$. This set of results further increases our confidence in the findings of model 3.

Our next robustness check involves assessing whether in-state and out-of-state postal expan- 


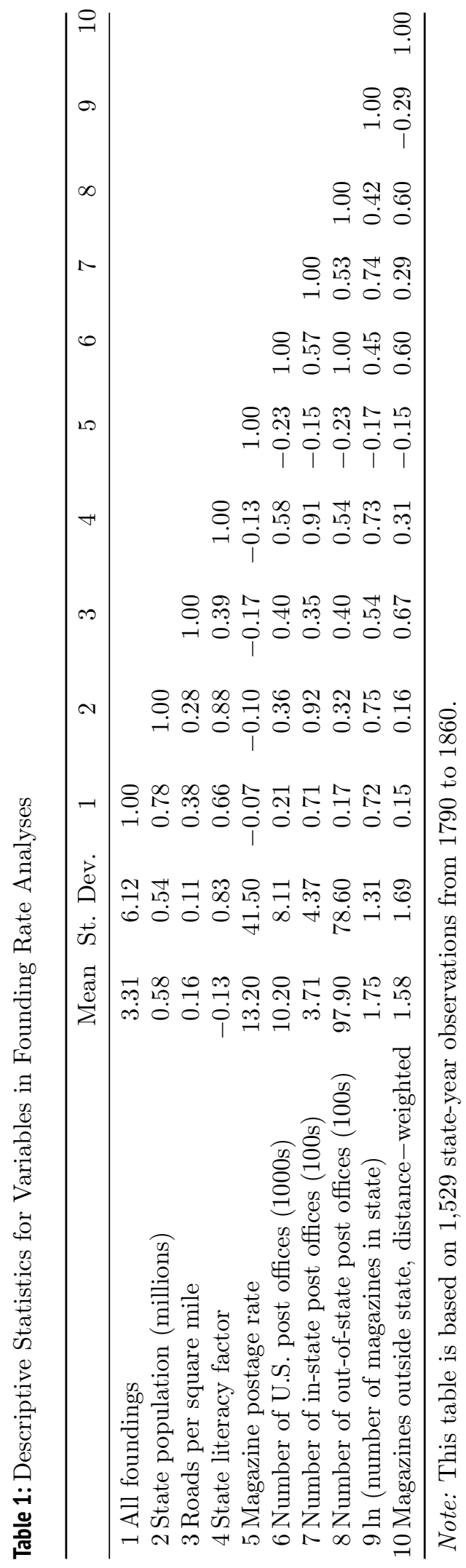




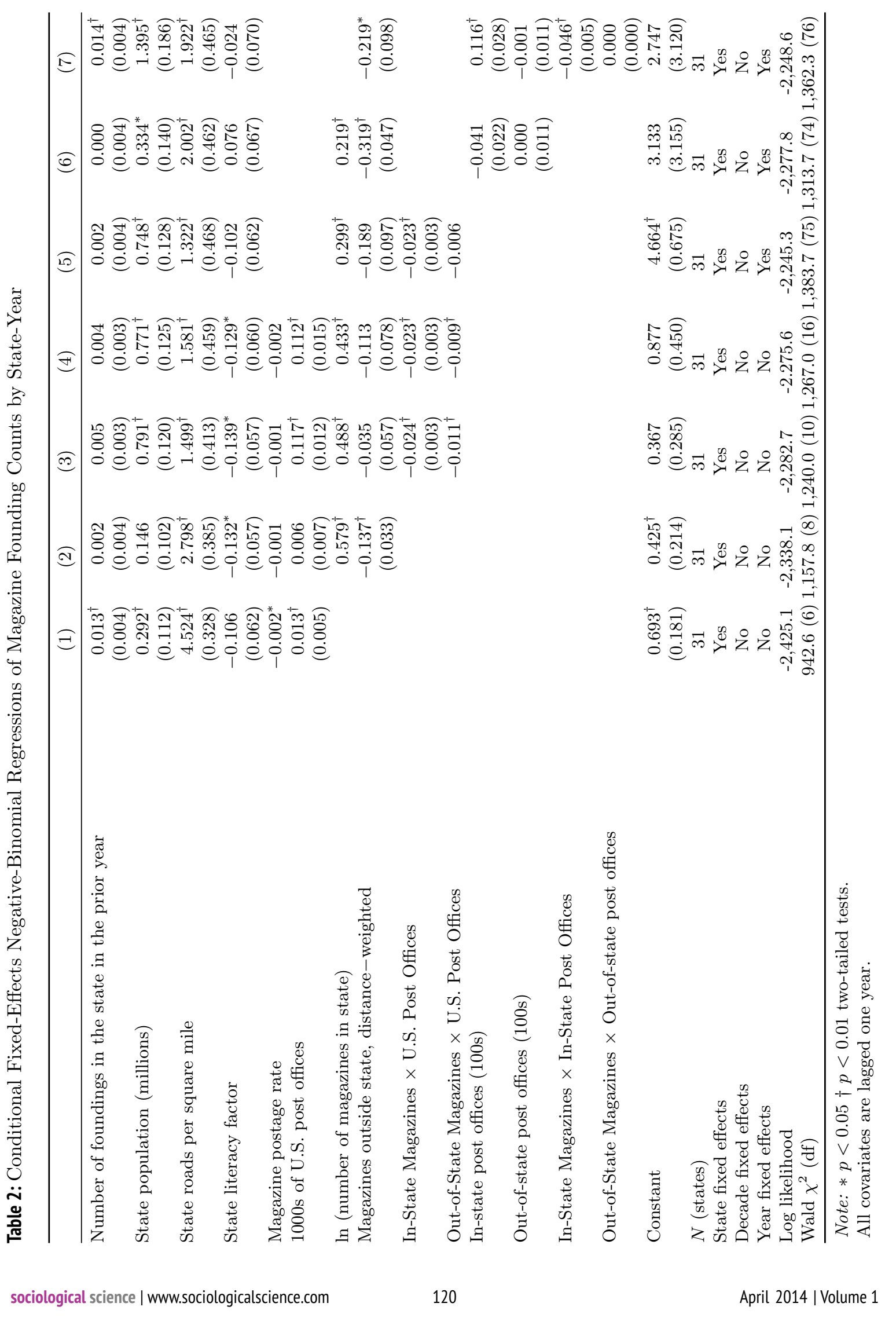




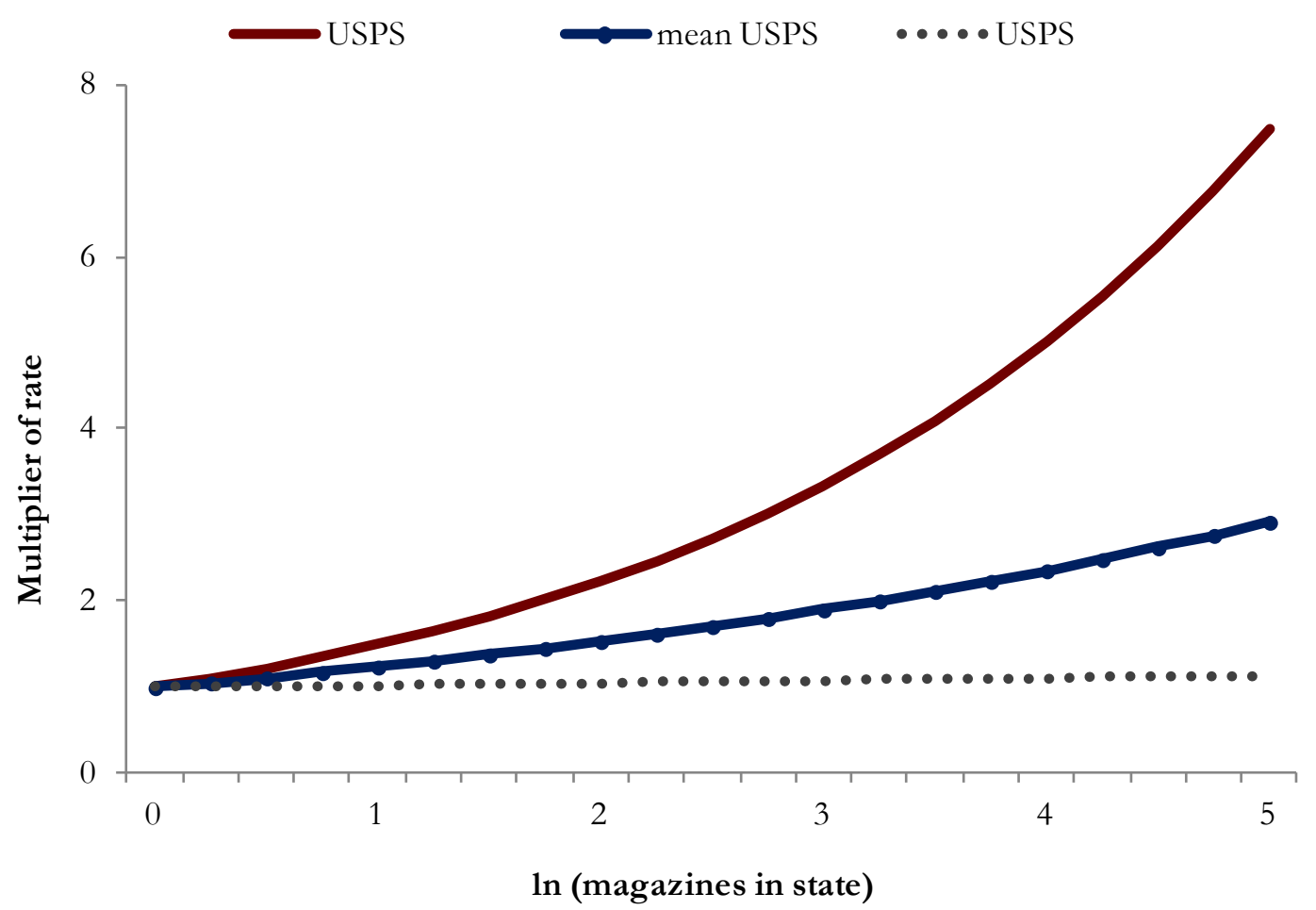

Figure 1a: The effect of in-state magazines on founding rates.

sion have different effects on magazine founding rates. We do this by disaggregating the number of US post offices into the number of in-state and out-of-state post offices. This allows us to include both year fixed effects and the main effects of postal expansion because both in-state and outof-state post office counts vary across states each year. Model 6 includes the main effects of instate and out-of-state post offices, whereas model 7 includes interactions between each post office count with the corresponding magazine count (instate or out-of-state). As these models show, the competitive effects of postal expansion on magazine founding rates are primarily attributable to in-state postal expansion.

To assess how much postal expansion alters the effects of local and nonlocal organizations on founding rates, we computed the multiplier of the baseline founding rate as a function of the logged number of in-state magazines and the distancescaled number of out-of-state magazines (both variables at their means) for three different levels of US postal system development: the mean num- ber of US post offices, the mean plus 1 standard deviation, and the mean minus 1 standard deviation. These effects use coefficients from model 4 of Table 2 because we need a coefficient for the post office main effect to compute multipliers. These multipliers are charted in Figure 1a (for instate magazines) and Figure 1b (for out-of-state magazines).

In Figure 1a, at the mean logged number of in-state magazines (1.75) and the mean number of US post offices, the multiplier of the base rate is 1.46. A 1-standard-deviation increase in the number of post offices decreases the multiplier to 1.05 (a decrease of almost 30 percent), whereas a 1-standard-deviation decrease in the number of post offices increases the multiplier to 2.02 (an increase of almost 40 percent). In Figure 1b, at the mean distance-scaled number of out-ofstate magazines (1.58) and the mean number of US post offices, the multiplier of the base rate is 0.72 . A 1-standard-deviation decrease in the number of post offices decreases the multiplier to 0.65 (a decrease of 10 percent), whereas a 


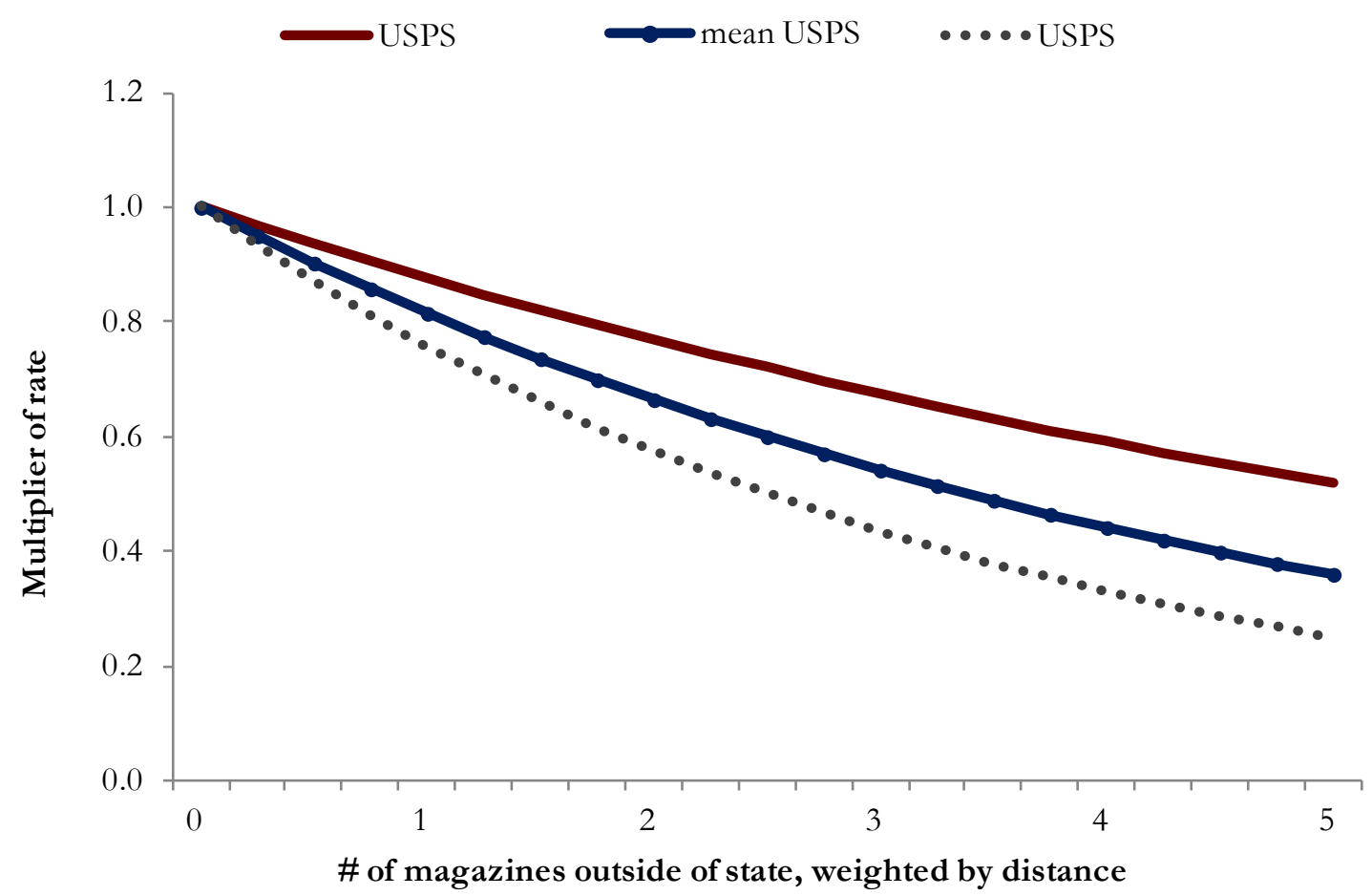

Figure $1 \mathrm{~b}$ : The effect of out-of-state magazines on founding rates.

1-standard-deviation increase in the number of post offices increases the multiplier to 0.81 (an increase of 13 percent). Thus, while the expansion of the post office substantially attenuated the beneficial effect of local magazines on subsequent local foundings, it only slightly accentuated the competitive effect of nonlocal magazines. This suggests that magazines in any focal location gained far more from being able to reach readers in ever-more-distant locations than they lost from other magazines published in those ever-moredistant locations reaching readers in their own location.

One possible concern with these results is that they might be driven by the increasing physical scale of our units of analysis: the thirteen original states were much smaller than states formed later. Such increases in physical scale complicate any analysis of geography. To assess this possibility, we reestimated model 4 from Table 2 using data on just the 13 original states. The results for these states, which are not shown here to save space, are almost identical to the results for the entire United States, which suggests that our findings are robust to increases in the physical scale of the units studied.

\section{Discussion and Conclusion}

In this study, we examined the impact of evolving communication systems on the geographic scope of competition and, specifically, on organizational founding rates. The development of communication systems brings distant actors closer to each other and so attenuates the relevance of space and erodes the distinctiveness of place (McLuhan 1962; Janelle 1968; Pred 1973, 1980; Kern 1983; Giddens 1990; Friedland and Boden 1994) This suggests that as communication systems develop new ventures increasingly compete against evermore-distant organizations.

We tested these predictions by analyzing the earliest modern communication system, the U.S. postal system, from 1790 to 1860 and foundings of magazine-publishing ventures. We found that 
as the postal system developed, positive spillovers from local organizations (the logged number of magazines published in the focal state) decreased, while competition from nearby nonlocal organizations (the number of magazines published outside the focal state, scaled by their distance from the focal state) increased. This pair of findings supports the argument that lowered spatial barriers to interaction subject organizations to greater competitive influences of distant organizations and reduce the beneficial influences of nearby organizations.

\section{Scope Conditions}

Our analysis is subject to two scope conditions. First, although the organizations we studied were overwhelmingly single-unit organizations (only a few publishing concerns produced multiple magazines in this era), our results should generalize to multiunit organizations - but they should apply more to organizations headquartered in the focal location than to those headquartered elsewhere for two reasons. First, locally headquartered multiunit organizations draw on more local resources than do remotely headquartered ones (Chandler 1977; Galaskiewicz 1979; Audia and Rider 2010). Second, managers of locally headquartered multiunit organizations are more likely to have careers that unfold in the focal locality than those of remotely headquartered ones; therefore, the managers of locally headquartered multiunit organizations are more deeply embedded in their locality than those of remotely headquartered ones (Molotch 1976; Galaskiewicz 1979; Friedland and Palmer 1984).

Second, our arguments apply only to organizations that produce offerings that can be transported and consumed across space. Empirically, this means all manufacturing firms but only a subset of service firms. Manufactured goods are physical objects that can be stored and moved across space, whereas only a few kinds of services can be stored and transported across spacemost notably, those involving information that is stored, physically or electronically, and transported across space using telecommunication systems.

\section{Future Research}

Although scholars clearly distinguish space (distance) and place (location), our study focused almost exclusively on entrepreneurship's relationship to space. Future research might build on our study by investigating how diminishing spatial barriers to competition influence the relationship between entrepreneurship and place. On one hand, place of production might become less relevant as offerings are increasingly produced in one place and consumed in another, and as offerings produced in more and more places enter consumers' choice sets. On the other hand, place of production might become an increasingly viable basis for competitive differentiation if consumers increasingly demand offerings with local connections (Giddens 1990). It might also be the case that as consumers evaluate offerings produced in more and more places, place of production becomes more salient.

Scholars could also build on our findings by examining more recent advances in communication systems. Perhaps the most obvious extension is to investigate how the Internet has reshaped the geography of news media organizations. The answer to this question is not at all clear. Although the Internet offers news media wider, effectively global, influence, there has also been a surge in localistic Internet sites that have replaced localistic print media. For instance, after the Seattle Post-Intelligencer shifted to online delivery only, its readership increased, even though its editorial staff shrunk by 75 percent (Kafka 2009).

\section{References}

Agnew, John A. 1987. Place and Politics: The Geographical Mediation of State and Society. Boston: Allen and Unwin.

Anderson, Benedict. 1991. Imagined Communities: Reflections on the Origin and Spread of Nationalism. Rev. ed. London: Verso.

Appold, Stephen. 2005. "Location Patterns of US Industrial Research: Mimetic Isomorphism and the Emergence of Geographic Clusters." Regional Studies 39:17-39. http://dx.doi org/10.1080/0034340052000320833 
Audia, Pino G., John H. Freeman, and Paul Reynolds. 2006. "Organizational Foundings in Community Context: Instruments Manufacturers and Their Interrelationship with Other Organizations." Administrative Science Quarterly 51:381-419. http://dx.doi.org/ 10.2189/asqu.51.3.381

Audia, Pino G. and Christopher I. Rider. 2010. "Close, but Not the Same: Locally Headquartered Organizations and Agglomeration Economies in a Declining Industry." Research Policy 39:360-74. http://dx.doi.org/10 1016/j.respol.2010.01.007

Bigelow, Lyda S., Glenn R. Carroll, Marc-David Seidel, and Lucia Tsai. 1997. "Legitimation, Geographical Scale, and Organizational Density: Regional Patterns of Foundings of American Automobile Producers, 1885-1981." Social Science Research 26:377-98. http: //dx.doi.org/10.1006/ssre.1997.0591

Boylan, Anne M. 1988. Sunday School: The Formation of an American Institution, 17901880. New Haven, CT: Yale University Press.

Brown, Richard D. 1976. Modernization: The Transformation of American Life 1600-1865. Prospect Heights, IL: Waveland Press.

Carroll, Glenn R. and James Wade. 1991. "Density Dependence in the Organizational Evolution of the American Brewing Industry across Different Levels of Analysis." Social Science Research 20:271-302. http://dx.doi.org/ 10.1016/0049-089X(91) 90008-Q

Chandler, Alfred D., Jr. 1977. The Visible Hand: The Managerial Revolution in American Business. Cambridge, MA: Harvard University Press.

Dahl, Michael S. and Olav Sorenson. 2010. "The Social Attachment to Place." Social Forces 89:633-58. http://dx.doi.org/10 $1353 /$ sof . 2010.0078

Daniel, Edward G. 1941. "United States Postal Service and Postal Policy, 1789-1860" PhD dissertation, Department of History, Harvard University.

Eaton, B. Curtis and Richard G. Lipsey. 1982. "An Economic Theory of Central Places." Economic Journal 92:56-72. http://dx.doi org/10.2307/2232256
Eisenstein, Elizabeth L. 1979. The Printing Press as an Agent of Change: Communications and Cultural Transformations in EarlyModern Europe. 2 vols. Cambridge: Cambridge University Press.

Festinger, Leon, Stanley Schacter, and Kurt Back. 1950. "The Spatial Ecology of Group Formation." Pp. 33-59 in Social Pressures in Informal Groups. Stanford, CA: Stanford University Press.

Fischer, Claude S. 1992. America Calling: A Social History of the Telephone to 1940. Berkeley: University of California Press.

Freeman, John H. 1986. "Entrepreneurs as Organizational Products: Semiconductor Firms and Venture Capital Firms." Advances in the Study of Entrepreneurship, Innovation, and Economic Growth 1:33-52.

Freeman, John H. and Pino G. Audia. 2006. "Community Ecology and the Sociology of Organizations." Annual Review of Sociology 32:145-69. http://dx.doi.org/10.1146/ annurev.soc.32.061604.123135

Friedland, Roger and Deirdre Boden, eds. 1994. NowHere: Space, Time, and Modernity. Berkeley: University of California Press.

Friedland, Roger and Donald Palmer. 1984. "Park Place and Main Street: Business and the Urban Power Structure." Annual Review of Sociology 10:393-416. http://dx.doi.org/ 10.1146/annurev.so.10.080184.002141

Galaskiewicz, Joseph. 1979. "The Structure of Community Organizational Networks." Social Forces 57:1346-64.

Giddens, Anthony. 1990. The Consequences of Modernity. Palo Alto, CA: Stanford University Press.

Gieryn, Thomas F. 2000. "A Place for Space in Sociology." Annual Review of Sociology 26:46396. http://dx.doi.org/10.1146/annurev soc.26.1.463

Hafner, Katie and Matthew Lyon. 1996. Where Wizards Stay Up Late: The Origins of the Internet. New York: Simon and Schuster.

Hannan, Michael T., Glenn R. Carroll, Elizabeth A. Dundon, and John Charles Torres. 1995. "Organizational Evolution in a Multinational Context: Entries of Automobile Manufacturers in Belgium, Britain, France, Germany, and 
Italy." American Sociological Review 60:509 28. http://dx.doi.org/10.2307/2096291

Hannan, Michael T. and John Freeman. 1989. Organizational Ecology. Cambridge, MA: Harvard University Press.

Haveman, Heather A. 2004. "Antebellum Literary Culture and the Evolution of American Magazines." Poetics 32:5-28. http://dx doi.org/10.1016/j.poetic.2003.12.002

Haveman, Heather A. 2013. "Bound by Print: Magazines, Community, and the Modernization of America, 1741-1860." Unpublished manuscript.

Hillier, Bill and Julienne Hanson. 1984. The Social Logic of Space. Cambridge: Cambridge University Press. http://dx.doi.org/10 1017/CB09780511597237

Janelle, Donald G. 1968. "Central-Place Development in a Time-Space Framework." Professional Geographer 20:5-10. http://dx.doi org/10.1111/j.0033-0124.1968.00005.x

Janelle, Donald G. 1969. "Spatial Reorganization: A Model and Concept." Annals of American Geographers 59:34864. http://dx.doi.org/10.1111/j 1467-8306.1969.tb00675.x

John, Richard R. 1995. Spreading the News: The American Postal System from Franklin to Morse. Cambridge, MA: Harvard University Press.

Kafka, Peter. 2009. "Hearst: Zombie Seattle Paper Doing Better Than the Original." http://allthingsd.com/20090518/hearstzombie-seattle-paper-doing-better-than-theoriginal/.

Katan, George and James N. Morgan. 1952. "A Quantitative Study of Factors Determining Business Decisions." Quarterly Journal of Economics 66:67-90. http://dx.doi.org/ $10.2307 / 1882077$

Kern, Stephen. 1983. The Culture of Time and Space, 1880-1918. Cambridge, MA: Harvard University Press.

Kielbowicz, Richard B. 1989. News in the Mail: The Press, Post Office, and Public Information, 1700-1800s. New York: Greenwood Press.

Krugman, Paul. 1991. "Increasing Returns and Economic Geography." Journal of Political
Economy 99:483-99. http://dx.doi.org/ $10.1086 / 261763$

Larson, John Lauritz. 1987. "'Bind the Republic Together': The National Union and the Struggle for a System of Internal Improvements." Journal of American History 74:36387. http://dx.doi.org/10.2307/1900027

Logan, John R. 2012. "Making a Place for Space: Spatial Thinking in Social Science." Annual Review of Sociology 38:507-24. http://dx.doi.org/10.1146/ annurev-soc-071811-145531

Lomi, Alessandro and Erik R. Larsen. 1996. "Interacting Locally and Evolving Globally: A Computational Approach to the Dynamics of Organizational Populations." Academy of Management Journal 36:1287-1321. http: //dx.doi.org/10.2307/257000

Marquis, Christopher. 2003. "The Pressure of the Past: Network Imprinting in Intercorporate Communities." Administrative Science Quarterly 48:655-89.

Marquis, Christopher and Julie Battilana. 2009. "Acting Globally but Thinking Locally? The Enduring Influence of Local Communities on Organizations." Research in Organizational Behavior 29:283-302. http://dx.doi.org/ $10.2307 / 3556640$

Marshall, Alfred. 1920. Principles of Economics: An Introductory Volume. London: Macmillan.

Marshall, Gloria J. 1995. "The Survival of Colleges in America: A Census of Four-Year Colleges in the United States 1636-1973." PhD dissertation, School of Education Stanford University.

McCusker, John J. 2001. How Much Is That in Real Money? A Historical Commodity Price Index for Use as a Deflator of Money Values in the Economy of the United States. 2nd ed., rev. and enlarged. Worcester, MA: American Antiquarian Society.

McLuhan, Marshall. 1962. The Gutenberg Galaxy: The Making of Typographic Man. Toronto: University of Toronto Press.

Miles, Pliny. 1855. Postal Reform: Its Urgent Necessity and Practicability. New York: Stringer and Townsend.

Molotch, Harvey. 1976. "The City as a Growth Machine: Toward a Political Economy of 
Place." American Journal of Sociology 82:30931. http://dx.doi.org/10.1086/226311

Mott, Frank Luther. 1930-38. A History of American Magazines. 2 vols. Cambridge, MA: Harvard University Press.

Mueller, Eva and James N. Morgan. 1962. "Location Decisions of Manufacturers." American Economic Review 52:204-17.

Porter, Michael. 1990. The Competitive Advantage of Nations. New York: Free Press.

Pred, Allan R. 1973. Urban Growth and the Circulation of Information: The United States System of Cities, 1790-1840. Cambridge, MA: Harvard University Press.

Pred, Allan R. 1980. Urban Growth and CitySystems in the United States, 1840-1860. Cambridge, MA: Harvard University Press.

Rich, Wesley Everett. 1924. The History of the United States Post Office to the Year 1829 Cambridge, MA: Harvard University Press.

Ringwalt, J. Luther. 1888. Development of Transportation Systems in the United States. Philadelphia: Railway World Office.

Sassen, Saskia. 2012. Cities in a World Economy. Los Angeles, CA: Pine Forge Press.

Saxenian, Annalee. 1994. Regional Advantage: Culture and Competition in Silicon Valley and Route 128. Cambridge, MA: Harvard University Press.

Soltow, Lee and Edward W. Stevens. 1981. The Rise of Literacy and the Common School in the United States: A Socioeconomic Analysis to 1870. Chicago: University of Chicago Press.

Sorenson, Olav and Pino G. Audia. 2000. "The Social Structure of Entrepreneurial Activity: Geographic Concentration of Footwear Production in the United States, 1940-1989." American Journal of Sociology 106:424-62. http://dx.doi.org/10.1086/316962

Stahl, Konrad. 1982. "Differentiated Products, Consumer Search, and Locational Oligopoly." Journal of Industrial Economics 31:97-113. http://dx.doi.org/10.2307/2098007

Starr, Paul. 2004. The Creation of the Media: Political Origins of Modern Communications. New York: Basic Books.

sociological science | www.sociologicalscience.com
Suire, Raphaël and Jérôme Vincente. 2009. "Why Do Some Places Succeed When Others Decline? A Social Interaction Model of Cluster Viability." Economic Geography 9:381-404. http://dx.doi.org/10.1093/jeg/lbn053

Swaminathan, Anand and Gabriele Wiedenmayer. 1991. "Does the Pattern of Density Dependence in Organizational Mortality Rates Vary across Levels of Analysis? Evidence from the German Brewing Industry." Social Science Research 20:45-73. http://dx.doi.org/10 1016/0049-089X(91)90003-L

Taylor, George Rogers. 1951. The Transportation Revolution 1815-1860. New York: Rinehart.

Tebbel, John and Mary Ellen Zuckerman. 1991. The Magazine in America, 1741-1990. New York: Oxford University Press.

Thompson, John B. 1995. The Media and Modernity: A Social Theory of the Media. Stanford, CA: Stanford University Press.

U.S. Bureau of the Census. 2001. Statistical Abstract of the United States. http://www census.gov/statab/www/

Wiebe, Robert H. 1984. The Opening of American Society: From the Adoption of the Constitution to the Eve of Disunion. New York: Knopf.

Zboray, Ronald J. 1993. A Fictive People: Antebellum Economic Development and the American Reading Public. New York: Oxford University Press. 
Acknowledgements: This research was funded by grants from the National Science Foundation (SES-0727502 and SES SES-0096016), the Ewing Marion Kauffman Foundation, and the Institute for Research on Labor and Employment at the University of California, Berkeley. We thank Adam Goldstein and Jacob Habinek for research assistance with the data on Sunday schools and colleges. We appreciate comments from Joe Galaskiewicz, David Kirsch, Chris Marquis, Giacomo Negro, and Toby Stuart as well as from seminar participants at Harvard Business School, UC Berkeley's Institute for Research on Labor and Employment, the Maryland Entrepreneurship Research Conference, the 15th Annual Meeting of Organizational Ecologists, and UC Berkeley's Institute for the Study of Societal Issues. Direct correspondence to Heather A. Haveman.

Heather A. Haveman: University of California, Berkeley. E-mail: haveman@berkeley.edu.

Christopher I. Rider: Emory University. E-mail: chris.rider@emory.edu. 